\title{
THE CONTEMPORARY AUTOMATIC GEARBOXES - REVIEW OF THE CURRENT STATE AND INTERPRETATION OF ADVANTAGES AND DISADVANTAGES OF THEIR USE WITH RESPECT TO VEHICLE PERFORMANCE AND TRAFFIC SAFETY
}

\author{
Darko Stanojević* \\ University of Belgrade, Faculty of Mechanical Engineering, Belgrade, Serbia \\ Vladimir Spasojević \\ SDT Group DOO, Belgrade, Serbia \\ Igor Stevanović \\ Porsche Beograd Ada , Belgrade, Serbia \\ Aleksandar Nedić \\ Insurance Company Dunav, Belgrade, Serbia
}

The aim of this paper is to present the current state of development level of contemporary automatic gearboxes in the automotive industry, their level of presence, as well as to bring the concept of a possible positive impact of their use on road safety as a solution designed with a high percentage of electronic components and cybernetics. The first section provides an overview of the types of automatic gearboxes in recent time and a short description of their function principles. The second section provides interpretation of possible positive efects of their using in automotive industry with respect to vehicle performance and traffic safety.

Keywords: Contemporary automatic gearboxes, Traffic safety, Vehicle performance, Automotive industry

\section{INTRODUCTION}

Nowadays motor vehicles have equipment which makes driving more comfortable, safer and reliable for drivers during exploitation of vehicle. Automotive manufactures are pressured to deliver complex products with increased quality in shorter development cycles. Engineering the performance of mechanical designs with traditionally test-based development processes are no longer an option [03]. New technologies include not only the systems that have been designed in the traditional way, i.e. systems that only include mechanical and electronic components, but also those that include communication models, control mechanisms, which work principle is based on information theory, computer and transmission signal theory, feedback theory. [02] In last few decades it can be said that vehicles play a key role in theory which explains connection and relationship "man-machine". The modern age would be almost unthinkable without the high presence of this transportation asset. Currently, technical characteristics and performances of vehicle systems are highly developed and new technologies provide higher safeness and comfort during driving. Although the drivers perception and reactions during driving still play a key role in traffic safety, thanks to the different new age vehicle systems in accordance with their development, safe motion of vehicle increasingly less depends on driver behavior. Nevertheless, user requirements of motor vehicles are increasingly higher in terms of performance, but so that increasing effect does not have influence on their safeness. The most merit for positive effect of ratio perfomances-saffness has high participation of the mechanical, electronic, computing and communication components in vehicle systems. Among the systems such as Electronic Stability 
Program (ESP), the adaptive cruise control, the lane change warning system, the assisted parking system, the multiplexed systems and connectivity could be considered as part of the new vehicle technology, there are also found contemporary automatic gearboxes such as intelligent or auto adaptive gearboxes and Automatic-sequential gearboxes (manumatic - tiptronic, geartronic, touch shift, sporttronic) and others. [02] The question arises: How can the using of automatic transmissions affect traffic safety? Generally, when the topic is vehicle safety, automatic gearboxes, as part of vehicle transmission, belong to the active elements of vehicle safety, because effect of their failure leads directly to traffic accident. In terms of vehicle performance, positive effects of using automatic gearboxes are proven and well-known [08]:

- increasing lifetime of engine and transmission

- increasing of dynamic characteristics of vehicle

- increasing of vehicle patency

- increasing of productivity of vehicle

- reduction of toxicity of exhaust gases

In terms of relationship „man-machine”, or in this case in terms of ergonomically view of vehicle design, there is a different interpretation of positive effects of using automatic transmission. In this paper beside interpretation of current state of development level of contemporary automatic gearboxes, is also represented one approach of interpretation of using automatic transmissions with respect to traffic safety.

\section{CONTEMPORARY AUTOMATIC GEARBOXES}

Words automatism and automatic comes from Greek language and denote the science of selfmovement, i.e. denote something that works by itself. Automatic transmission is one of the most complex subsystems in motor vehicles. Design of automatic transmissions demands knowledge of the numerous areas of technology, not only mechanical but also others, especially electronic area. More than 100 components demand not only the precise manufacture, small masses, compact solutions and reliable operation, but also the easy and fast maintenance and easy changing of gears in all exploitation conditions. The aim of every automatic transmission designer is to realize such components which will have all mentioned qualities and at the same time low price. First automatic gearboxes have appeared in USA at the end of 40's of the last century but during the 50's, $70 \%$ of vehicles already have automatic transmission. At the beginning of 2000 -ies even $90 \%$ of vehicle have automatic gearboxes while their participation in Japan was $70 \%$ and in Europe only 16\%. (Figure 1)

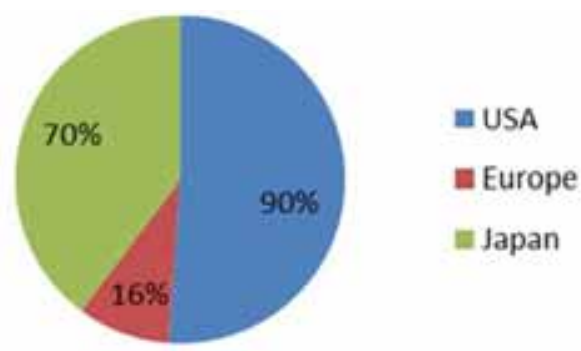

Figure 1: Participation of automatic transmission on vehicles at the beginning of 2000-ies in the world

Till the 80's automatic gearboxes had no electronic central unit to control the gears. The gear shift depended on the accelerator's position and the control was done by a set of valves that were moved by the oil pressure difference around them. It was a hydraulic control system. [02]

When electronics came into the market, at the end of the 80's the gear shifts were not done by mechanic references any more, but by a set of rules established by electronics. Several sensors measure the vehicle's speed, the accelerator's position and speed, the connected gear, etc. This information is received by the electronic central unit that sets the connected gear at every moment.

\section{Intelligent or auto adaptive gearboxes}

The aim of this transmission is to adapt to driver's needs and driving style, in every moment of vehicle movement, learning the driver's habits during vehicle operation. [02] These types of automatic transmission control use several behavior laws and next installed sensors are responsible for selecting of the most suitable law: accelerator's position and action speed, vehicle speed, engine torque, slope, gearbox temperature, etc.

Example of one intelligent or auto adaptive gearbox is type AL4. [04] This type of automatic transmissions can mostly be found on French vehicles of new generation such as CITROEN C5, PEUGEOT 308, 407 etc. Furthermore, in shorter terms will be presented technical description and working principle of this type of automatic transmissions. 
AL4 type includes following mechanical components:

\section{Converter}

2. Input shaft

3. Fitted oil pump

4. Secondary pinion of step down gear

5. Park wheel

6. Secondary shaft

7. Drive pinion

8. Ring

9. Differential unit

10. Cover

11. Adjustable plate
12. Hydraulic distributor (DH)

13. Manual valve

14. Auxiliary hydraulic distributor (DHA)

15. Clutch E1 (Reverse and 1st)

16. Clutch E2 (2nd, 3rd, 4th)

17. Hub

18. Brake F1 (4th)

19. Brake F2 (Reverse)

20. Brake F3 (1st and 2nd)

21. Epicyclical gear train

22. Primary pinion of step down gear [04]

All mechanical components of AL4 automatic gearbox can be seen on figure 2 .

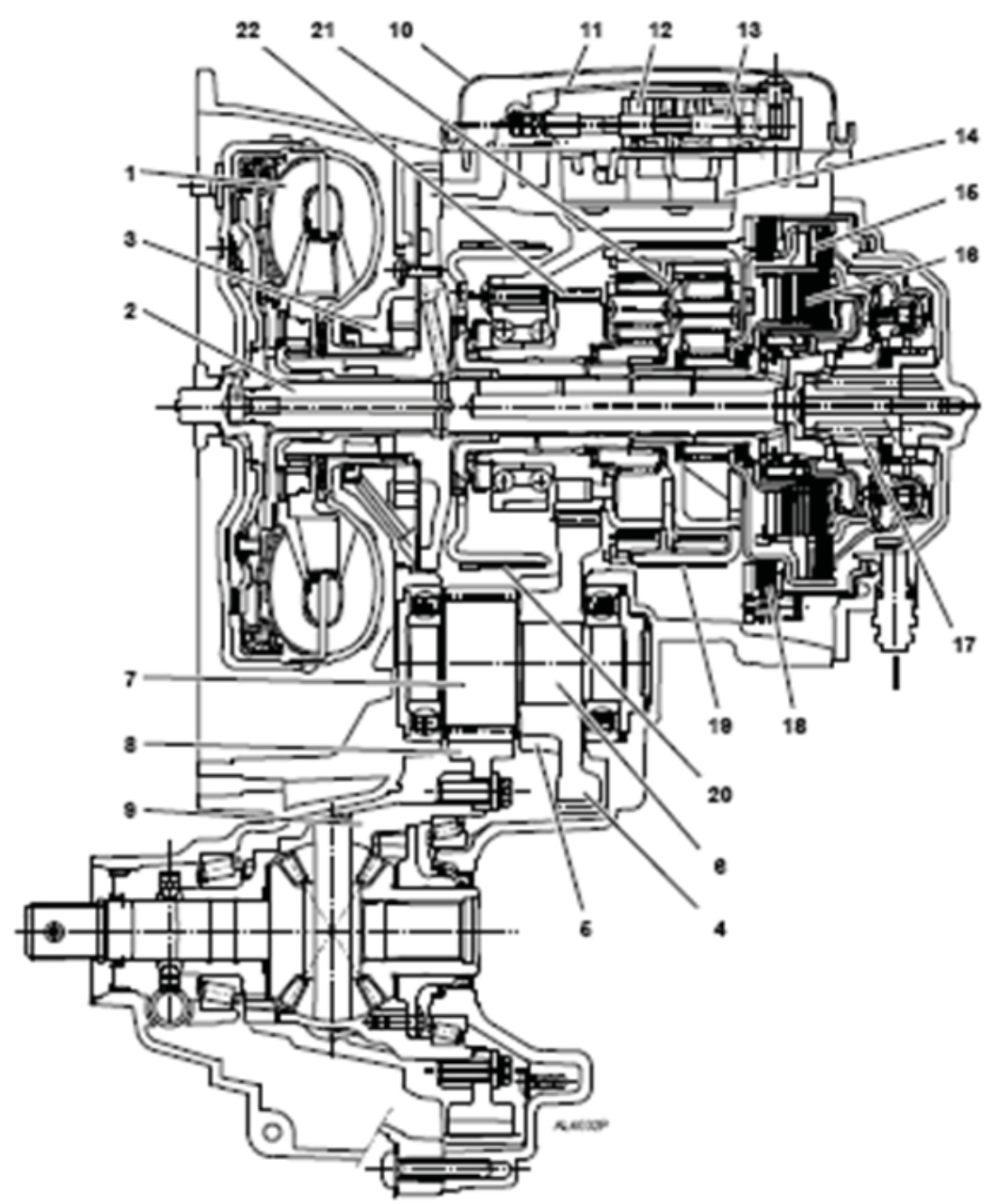

Figure 2: Cross-section of AL4 automatic transmission [04]

Auto adaptive or intelligent control at this type of automatic gearbox is provided by:

- Hidraulic control unit

- Electronic control unit (ECU)

- Electronic participation
Gear changing are performed automaticly and depends on vehicle speed and loads of engine. Laws of gear changing are selected by ECU in function of 3 driving modes:

- Auto adaptive or normal mode, basic mode; 
ECU provides adaptation to the driver habits, load of engine, road profile.

Characteristic of this mode is economic driving or low consumption of gas

- Sport mode - fast driving. Characteristic of this mode is higher consumption, but still performed automatic gear changing automatic

- Snow mode - mode for driving on surface with low adhesion [04]

Electronic control unit (ECU) automatically activates normal mode, every time when vehicle is in that kind of exploatation conditions.

Electronic control unit (ECU) provides 10 gear changing laws during transmission, in accordance with drivers habits, chosen drive mode and internal and external conditions:

- 6 laws: for autoadaptivity,

- 1 law: for the snow program,

- 1 law: "unlocked" for low temperature operation,

- 1 law: for depollution when cold (heating),

- 1 law: for automatic transmission temperature protection.

So, AL4 automatic gearbox provides precise adaptive control as well as good quality of gear changing.

\section{Automatic sequential gearboxes}

This type of automatic gearbox provides two work principles. First one is completely automatic, when gearbox performs itself selected gear, and second one is manual (sequential), when driver decides which gear is the most suitable for current driving, using the selector lever and this is the reason why this automatic gearboxes are also called manumatic, because they provide most suitable choice of transmission. [02] Control of gear selection manumatic is provided with selector lever implemented behind steering wheel or with modified selector lever implemented in tunnel between two seats, or with buttons on steering wheel, which for result gives easier control during driving. Different car producers are using various names for their manumatic gearboxes: Tiptronic, Geartronic, Touchshift, Sporttronic and other. Different between manumatic and semi-automatic gearboxes is in mode of transmission from engine to gearing. Manumatic is using torque converter as well as conventional automatic gearboxes, while semi-automatic gearboxes are using double or multiple clutches. Manumatic is more useful for everyday use because clutch in fluid provides smooth and insensibly gear changing. Manumatic and most semiautomatic transmissions offer ability to work on the same principle as conventional automatic gearboxes, letting the computer to choose the most suitable gear. The most present manumatic is Tiptronic. Tiptronic is registered trademark, owned by german sport car manufacure Porshe, which licensed it for other car producers, such as: Land Rover and Volkswagen Group (Audi, SEAT, Škoda and Volkswagen). [08]

Tiptronic transmission is equipped with intelligent electronic program for control which was developed in cooperation with Bosh. As well as many automatic transmissions tiptronic automatic transmission has got blocking clutch for torque converter which is switched in second, third and fourth gear, and in fifth gear in the newest version of tiptronic. Gear lever mode of tiptronic has two parallel trajectories. (Figure 3)

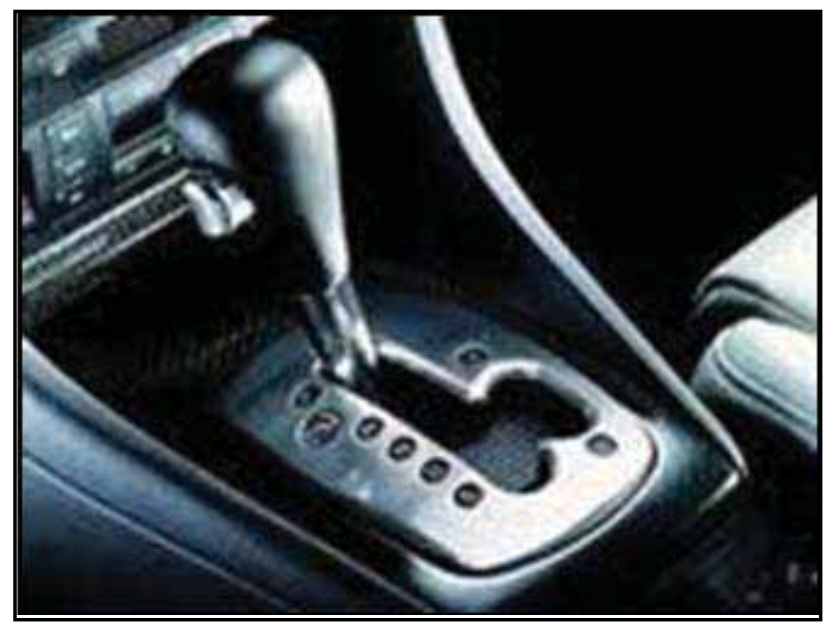

Figure 3: Lever for automatic or manual selection of gears in gear box-Tiptronic [08]

Left trajectory corresponds to standard automatic transmission with positions $P, R, N, D$ while right trajectory have position with tags "+", "-“ and $M$ which is designed for manual transmission. Launching the lever gear in direction "+" performs shifting to higher gear, while launching the lever gear in direction "-" performs shifting to a lower gear. In comparison with earlier transmissions with electronic control and "rigid" program control, Tiptronic control characteristic is adaptive. At sudden acceleration, electronic device recognize sport ambitions of driver behaviour and allows one extreme characteristic of gear changing. On the other hand, if driver 
drives too "soft", transmission is programmed to perform timely changing of gear to higher transmission. [08]

Between this two extremes are located three other possibilities of gear changing laws which correspond to all drivers behaviour. The concept of tiptronic control can be seen on Figure 4 .

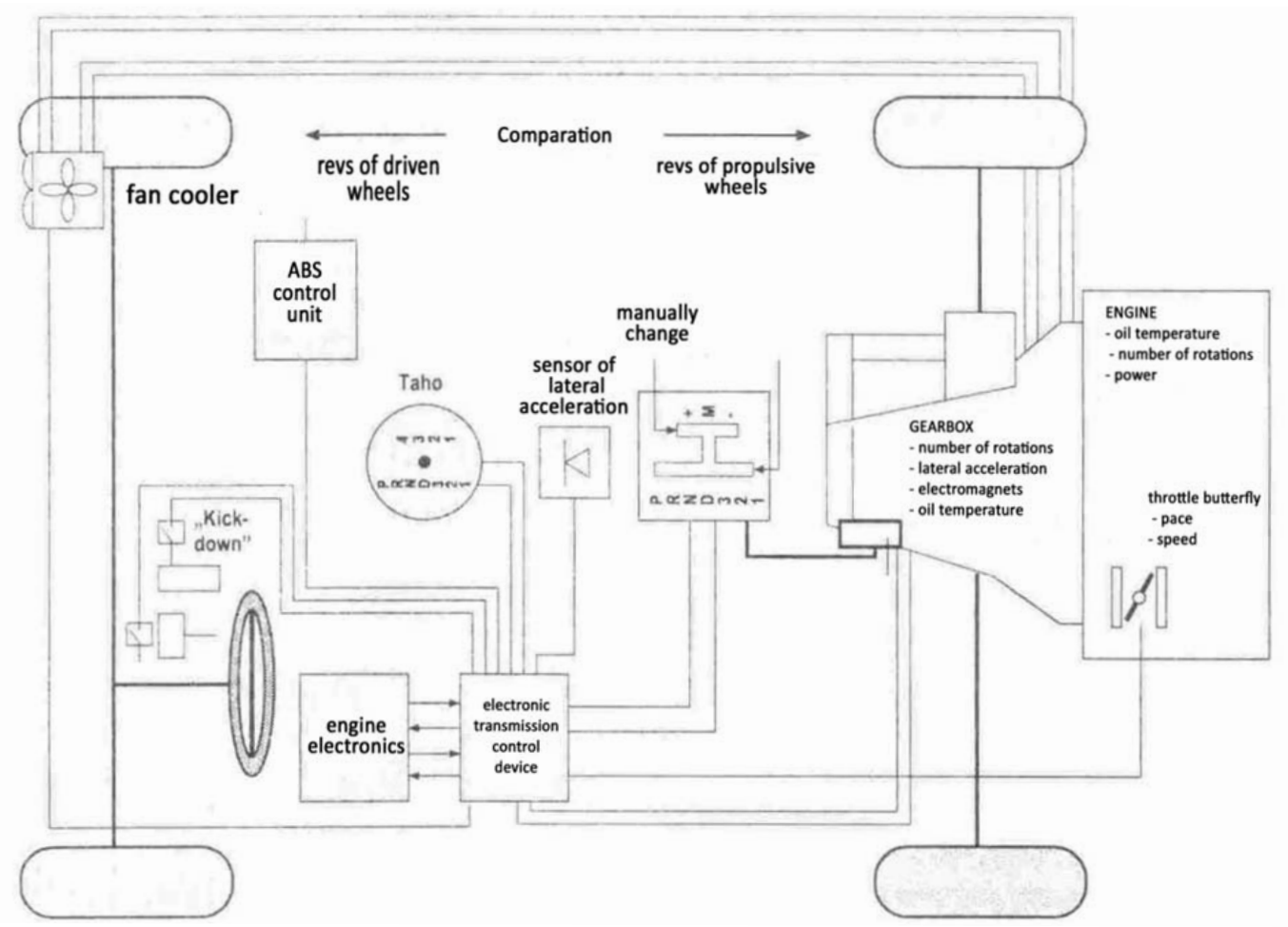

Figure 4: Concept of tiptronic control [08]

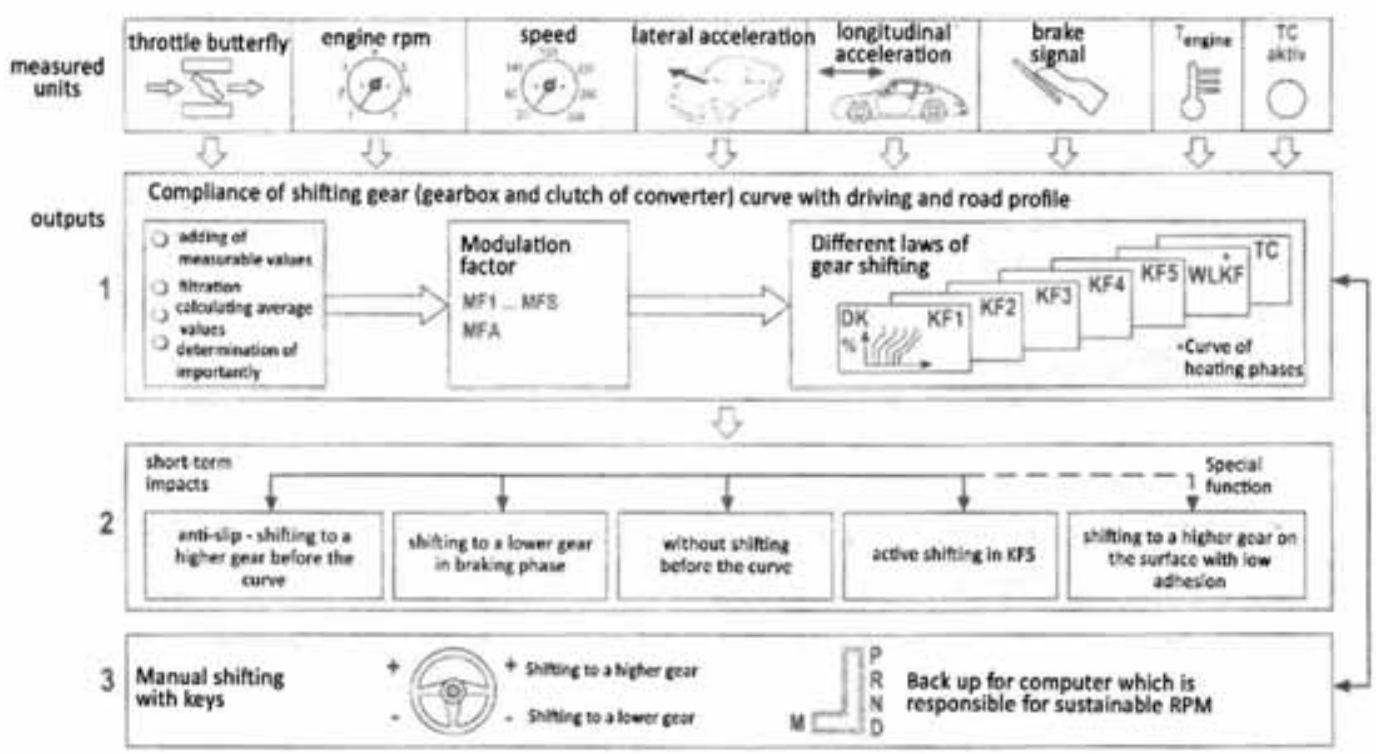

Figure 5: Programs of Tiptronic transmission control [08]

One significant parameter of tiptronic transmission control is speed of layoff of gas pedal. If speed of layoff is slow, for tiptronic control system that means further moving with current speed, and switching to higher gear. If speed of layoff of gas pedal is fast, for tiptronic transmis- sion that means switching to lower gear. Beside this it is very important that an unwanted change to a higher gear does not perform in curvature. In curvature, lateral acceleration sensor acts, which hold the most optimal gear for currently drive speed. Also with electronic, which is re- 
sponsible for control of automatic transmission is connected ABS (Anti - lock braking system) system. A sensor channel of ABS system provides traction control through regulation of gear. ABS control unit compares rotation number of driven and propulsive wheels and recognizes difference between their traction. $[09,08]$ At braking, in this situation, the automatic performs changing in higher gear, and thus prevents additional blocking of rear wheels. On figure 5 , it can be seen programs of control of Tiptronic transmission.

Control unit of tiptronic transmission control is eight-bit microcontroller with $32 \mathrm{~kb}$ of memory. This microcontroller processes information about vehicle speed, positions and speed of throttle butterfly, number of engine rotations (RMP), lateral and longitudinal acceleration of vehicle. Thereby, is mentioned electronic unit connected with engine electronic. According to these parameters different programs of tiptronic control are possible. If the shift lever is placed on position of automatic gear shifting, the possibilities of work principle of automatic transmission are following:

- At starting the vehicle, the automatic transmission works at the lowest program mode of gear shifting, according to the characteristic KF1, which provides the most comfort and fuel economy;

- If driver shows increasingly sports behaviour during driving, automatic transmission will recognize them, and will perform gear shifting according to the characteristic KF2, KF3, KF4 up to KF5 (sport characteristic). [08]

In base, electronic device is programmed to work at the lower characteristic, which means earlier gear shifting to a higher gear and later gear shifting to a lower gear. Thus, fuel consumption is optimised, noise and exhaust emissions are reduced. At quickly layoff of gas pedal, ahead of the curve, previous automatic transmissions reacted inadequately, performing gear shifting to a higher gear. Tiptronic transmission is better informed and do not react like that. Additional benefit includes possibilities of engine braking in current gear, which means absent of gear shifting in lower gear, when is exiting the curve. To the value of $0.4 \mathrm{G}$ of lateral acceleration, which were measured by sensor of lateral acceleration, automatic transmission do not react in curve and that means continual driving. Also, at surface with snow, ice i.e. at surface with low adhesion, elec- tronic reacts by switching the higher gear and prevents inadequately engine braking. If driver wants to be more active during driving is left possibility to shift the lever gear in right trajectory and then to shift gears by itself. However, in this case electronic also protects engine of the large number of RPM. Otherwise, during driving the driver has need to return lever gear from manual to automatic mode, because he quickly gets to conclusion that automatic transmission could do this function by itself.

During operation in automatic mode, electronic control unit needed $30-100$ milliseconds to process all information and to task appropriate commands. To switch from KF1 to KF5, it is necessary at least 30 seconds. Efficiency of adaptive transmission control depends of number of installed programs in computer and of number parameters which are determining them. Because constant tendency to sequential transmissions Porsche for model $911 \mathrm{~S}$ had launched new version of tiptronic transmission under the name Tiptronic S. Command of this tiptronic version is replaced from floor to steering wheel. Keys on steering wheel showed that they are more practical for shifting then commands on the floor. On the lever gear, on the tunnel between two seats, were left same marks for transmission operations in automatic mode as they have been in previous version of tiptronic.

Thanks to the high development programs for gear shifting, in practice is creating strong competition between automatic and conventional transmissions. Better acceleration of vehicle this transmission does not reach compared with conventional transmissions. However, thanks to the many number parameters which were placed in electronic, tiptronic have numerous benefits. The Computer program is open for learning and it is able to "Remember" driver's behaviour, among other things, also when driver manually shift gears.

\section{GPS - controlled automatic transmission}

It is good to mention the newest design solution of control of automatic transmissions. It has been launched this year, 2013, and it is GPS controlled transmission. Rolls-Royce engineers created this solution of control of automatic transmissions and call "Satellite Aided Transmission" (SAT). Control unit of eight-speed automatic transmission is linked to Global Position System (GPS) receiver. Vehicle with this kind of automatic transmission control uses satellites 
to constantly determine conditions of road profile. It then uses this data to anticipate how and when to shift gears. For example, if GPS determines twisty road and vehicle coming into a turn, this system holds currently gear, which is better than upshifting. GPS figures out what upcoming stretches of road look like, and pre-shifts accordingly. For example, it can downshift the moment a hill or curve is approached, which helps with both performance and fuel economy. Quite literally, it can be said, that Satellite Aided Transmission uses GPS data and the navigation system to scan the road. The navigation system compiles real-time traffic data and uses the data to update the travel route every three minutes. [05]

\section{ADVANTAGES AND DISADVANTAGES OF USING THE AUTOMATIC TRANSMISSION IN TERMS OF VEHICLE PERFORMANCE}

When the topic is automatic transmission it means transmission which work principle is completely opposite from manual. Automatic transmission works without often interruptions, with minimal appearance of shock loads, which for result gives comfortable driving. It is clear that transmission is performed automatically, and depends of vehicle speed, where hydraulic torque converter provides absence of clutch pedal, which for driver means relief of often suppression of clutch pedal, and therefore it increases comfortable in driving. [05]

In terms of fuel consumption, due to the complexity of the system and large energy loss in hydraulic torque converter, automatic transmission is not at an enviable level. Because of the mentioned reasons, vehicle with automatic transmissions are vehicles that could be characterized as vehicles with higher fuel consumption. [06] Also, in terms of maintenance, i.e. preventive and corrective maintenance vehicles with automatic transmission could be classified as vehicles with higher maintenance costs.

Automatic gear shifting, do not give choice of gear for the driver, so that is why it is possible absence of fast drive feeling. In terms of comfortable, automatic gearboxes are in advantage. Automatic transmission provides comfortable during driving, especially in conditions of "traffic jams", which could be described as "go-stop" traffic, because of absents of clutch pedal and manually gear shifting. Using of automatic gearboxes do not demand special driver skills, and due to the own automatic transmission, driver can more pay attention to the acceleration, steering and braking, which for results gives improve safeness in driving. Table 1 presents review of advantages and disadvantages of using automatic transmissions.

Table 1: Comparation of advantages and disadvantages of using automatic transmissions

\begin{tabular}{|c|c|}
\hline Advantages & Disadvantages \\
\hline increasing of comfort & $\begin{array}{c}\text { Increasing of } \\
\text { maintenance costs }\end{array}$ \\
\hline \hline simplicity of using & $\begin{array}{c}\text { Increasing of } \\
\text { fuel consumption }\end{array}$ \\
\hline \hline $\begin{array}{c}\text { Reducing presence of } \\
\text { shock loads }\end{array}$ & limited transmission \\
\hline
\end{tabular}

\section{TRAFFIC SAFETY IN TERMS OF AUTOMATIC TRANSMISSIONS}

Driving in complex traffic environments could be very difficult for drivers, especially in conditions of traffic where is present often interaction with other drivers. In that condition, it is concluded that older drivers increasingly lose power of quickly perception and reasoning. One of the prerequisites for safe driving is attention. When mental resources are not sufficient to meet all the impose tasks, the driver will see only the limited set of information which he will use for decision making and response to the demanding tasks [07]. According to the performed statistic, older drivers crash more frequently in complex traffic environments, then younger drivers and especially in intersections which involve turning, especially turning across the oncoming lane, and in complex traffic situations, i.e., when overtaking and merging. Results are contradictions about tactical performances of older drivers and driving skills. While some claim younger drivers make more driving errors than older drivers, older drivers have been found to have more problems with operational driving skills. In this case it was observed and performed comparison of driving skills of younger and older drivers in aspect of automatic and manually transmissions. More precisely it was compared one particular operational driving skill, gear changing, at younger and older drivers.

Research involved two groups of participants, population of older drivers, between the ages of 70 - 90 years, (average age 75.2) and population of younger drivers, between the ages of $27-48$ years (average age 39.2). All partici- 
pants drove the same route, one in vehicle with manually transmissions and one in vehicle with automatic transmissions. Each test took $35 \mathrm{~min}$, in city traffic, thus to every chosen route had to be diverse in terms of traffic complexity, i.e. to involve many crossroads, left and right turns, traffic signs. For evaluation of driver's skills during the tests, it was used ROA software (Ryd OnRoad Assessment). [01] ROA software is using scoring sheet which involve 34 specified items in seven categories (Table 2): speed, position, attention, indicator, manoeuvring, instructions, and traffic rules showed on figure 10. Made errors are graded on a 0-2 scale, where 0 implies normal driving behaviour, 1 indicates minor error, while 2 indicates considerable risk-taking behaviour. Results of performed tests are showing that the older group made more driving errors, both, in the car with manual transmission and in the automatic transmission car, compared with the younger group. [01] In the older group, driving the automatic transmission car improved their driving behaviour regarding the number of driving errors. However, the car with automatic transmission did not affect the driving behaviour for the younger group, except for the turning left-task.

Automatic transmission had positive impact on driver behaviour of older drivers in five driving items. The two showing the largest impacts were Manoeuvring - Change gear, indicating inappropriate gear usage and Speed-Too fast for the situation relating to problems with controlling the speed according to the situation. The other three items were Manoeuvring - Handling pedals, Traffic rules -Exceeding speed limit and Position - To the left.

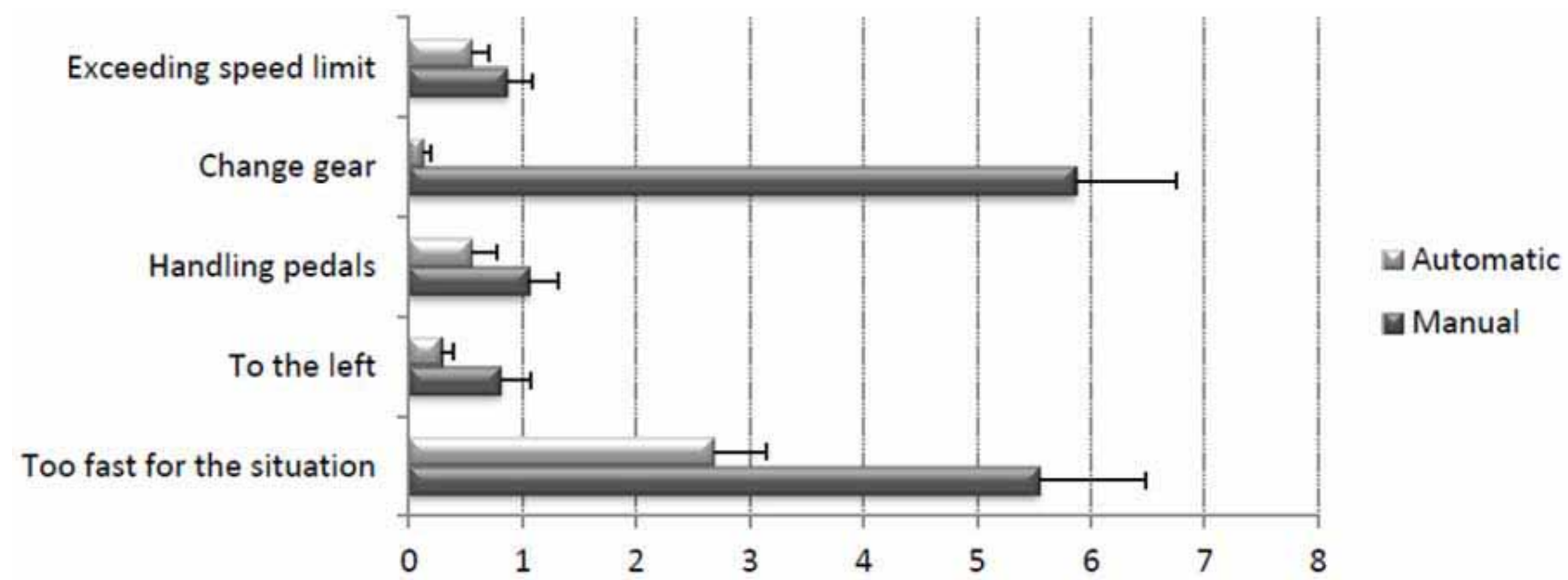

Figure 6: Items indicated in italics were the ones in which the automatic transmission car had a significantly positive impact for the older group, which is further displayed in the bar chart in the lower part of the figure.

The $X$-axis represents the average number of errors [01]

Table 2: Scoring sheet with 34 specified items in seven categories [01]

\begin{tabular}{|c|c|c|c|c|c|c|}
\hline 1.Speed & 2.Position & 3.Attention & 4.Indicator & 5. Manouvering & 6.Instructions & 7.Traffic rules \\
\hline $\begin{array}{l}\text { Too fost for } \\
\text { the situation }\end{array}$ & To the right & To the right & $\begin{array}{l}\text { No use of } \\
\text { indicator }\end{array}$ & Handling pedals & $\begin{array}{l}\text { Repeating } \\
\text { needed }\end{array}$ & $\begin{array}{l}\text { Give right of } \\
\text { way }\end{array}$ \\
\hline $\begin{array}{l}\text { Too slow for } \\
\text { the } \\
\text { situation }\end{array}$ & To the left & To the left & $\begin{array}{l}\text { Wrong } \\
\text { direction }\end{array}$ & Steering & $\begin{array}{l}\text { Reminding } \\
\text { needed }\end{array}$ & Yield to traffic \\
\hline $\begin{array}{l}\text { Slow/late } \\
\text { braking }\end{array}$ & $\begin{array}{l}\text { Close to the } \\
\text { vehicle in } \\
\text { front }\end{array}$ & Ahead & Too late & Change gear & $\begin{array}{l}\text { Drive the } \\
\text { wrong way }\end{array}$ & $\begin{array}{l}\text { Obligation to } \\
\text { stop }\end{array}$ \\
\hline \multirow[t]{3}{*}{$\begin{array}{l}\text { Braking } \\
\text { without } \\
\text { reason }\end{array}$} & \multirow[t]{3}{*}{$\begin{array}{l}\text { Sway } \\
\text { between } \\
\text { lanes }\end{array}$} & $\begin{array}{l}\text { To the rear } \\
\text { incl rear- } \\
\text { view mirror }\end{array}$ & Too early & $\begin{array}{l}\text { Manage } \\
\text { controls to the } \\
\text { left }\end{array}$ & & $\begin{array}{l}\text { Exceeding speed } \\
\text { limit }\end{array}$ \\
\hline & & $\begin{array}{l}\text { Blind spot, } \\
\text { to the right }\end{array}$ & \multirow[t]{2}{*}{$\begin{array}{l}\text { Does not } \\
\text { switch it off }\end{array}$} & $\begin{array}{l}\text { Manage } \\
\text { controls to the } \\
\text { right }\end{array}$ & & $\begin{array}{l}\text { Rules regarding } \\
\text { buses }\end{array}$ \\
\hline & & $\begin{array}{l}\text { Blind spot, } \\
\text { to the left }\end{array}$ & & Reverse & & $\begin{array}{l}\text { Crossing a solid } \\
\text { lane line }\end{array}$ \\
\hline
\end{tabular}


The present study found that the older participants' driving behaviour improved when driving a car with automatic transmission. As a result of the automatic transmission they displayed safer speed adjustments in urban areas, safer lane positioning, greater manoeuvring skills and better attention to the speed regulations while for younger drivers, automatic transmission had less effect on their driving behaviour. [01] Switching to automatic transmission may be recommended for older drivers as a means to maintain safe driving and thereby the quality of their transport mobility.

\section{CONCLUSION}

Contemporary technology is in constant development. Contemporary automatic transmissions and different methods for control automatic gearboxes such as intelligent or auto adaptive control; automatic sequential control or GPS-controlled transmissions are part of development, and present major role. Work principles of these methods of control of automatic gearboxes are described, and it is clearly that introduction of such controls provides increasing of safeness and proven better performances of motor vehicles. But, questions arise: Does such methods of controlling the automatic transmissions are better for drivers? Does really make driving more comfortable, pleasant and without stress? Opinions are divided. Interaction between drivers and system of motor vehicles, in this case interaction between drivers and gearboxes could be answer. For some drivers, it is better to have higher physical contact with road profile and for them that represents better controlling of vehicle transmission and furthermore better controlling of complete vehicle, while for some drivers absence of physical contact presents more comfortable and pleasant driving. Based on this it can be said that driving experiences decides whether to accept these types of automatic gearboxes. Intelligent or auto adaptive control is using learning of the driver's habits during vehicle operation to control transmission. Does driver's habits are always the same for all drivers? That could be reason for further research. Also it is good to mention one further remark about GPScontrolled transmissions. Currently road data for car navigation according to the driver's experiences, in many cases, is not complete and this method of controlling of automatic transmissions would require significantly better road data that is currently available. In order to be safe and functional it would need to know about the camber of corners, the inclinometer of hills and to be able to sense other vehicles in proximity and how they are being driven. Generally, it can be said that automatic transmission is widely accepted, but does this methods of controlling automatic transmissions is widely accepted remains to be answered to above mentioned questions.

\section{ACKNOWLEDGMENT}

This paper is part of research of the project: project number TR35045 (Scientific and technological support for improving the safety of special road and rail vehicles, project supported by Ministry of Education, Science and Technological development of Republic of Serbia.

\section{REFERENCES}

1) Falkmer, T., Selander, H., Bolin, I. (2011): "Why drive manual?-Automatic transmission improves driving behavior in older drivers", ARSRPE Conference

2) Francisco Gonzales de Prado: "Cybernetics applications in vehicles", Master in Cybernetics Research, University of León, September 2012

3) Glišović, J., Demić, M., Miloradović, D. (2011): Review of virtual reality applications for reducing time and cost of vehicle development cycle, Journal of Applied Engineering Science (Istraživanja i projektovanja u privredi), no. 3, vol.9, pp. 361-372

4) http://AL4\%20Transmission.pdf: Citroen technical training: "Presentation of AL4 automatic trasnmission"

5) http://www.autoblog.com/2013/03/04/rollsroyce-wraith-geneva-2013/

6) Mayur R. Mogre (2012): "Comparative study between Automatic and Manual transmission car", International conference on mechanical, Automobile and Biodiesel Engineering, pp. 308-312

7) Pavić, N., Popović, V., Vasić, M. (2011): Drivers age as the dominant demographic factor in traffic accident, Journal of Applied Engineering Science (Istraživanja i projektovanja u privredi), no. 3, vol.9, pp. 411-416

8) V.Spasojević (2012): Diplomski MSc rad: "Savremenamehatroničkarešenja-automatskimenjački prenosnici", Mašinski fakultet, Beograd

9) Živanović,Z.,Janićijević,N.(1999):Automatske transmisije motornih vozila, Beograd: Ecolibri

Paper sent to revision: 25.04.2013.

Paper ready for publication: 23.05.2013. 